\title{
EL EJERCICIO DE LA VIOLENCIA SIMBÓLICA EN LA ATENCIÓN EN SALUD DE MUJERES EN EDAD MEDIANA QUE EXPERIMENTAN LA MENOPAUSIA: PRINCIPALES RESULTADOS DE UNA ENCUESTA CAP
}

\section{THE EXERCISE OF SYMBOLIC VIOLENCE IN HEALTH CARE OF MIDDLE-AGE WOMEN EXPERIENCING MENOPAUSE: KEY RESULTS OF A KAP SURVEY}

\author{
Andrés Castillo Vargas* \\ Ivannia Chinchilla Badilla**
}

RESUMEN

\begin{abstract}
El presente artículo pretende analizar la violencia simbólica a la luz de los conocimientos, actitudes y prácticas que el personal de salud posee en torno a la atención de mujeres en edad mediana que experimentan la menopausia. A nivel metodológico, se planteó un estudio exploratorio-descriptivo, en el cual se utilizó el método de encuesta CAP (Conocimientos, Actitudes y Prácticas). Tal aproximación identificó como hallazgo principal, la necesidad de promover una ruptura paradigmática respecto a la visión tradicional del cese menstrual y a la manera en que su abordaje ha sido concebido.
\end{abstract}

PALABRAS CLAVE: MUJERES * EDAD MEDIANA * MENOPAUSIA * PERSONAL DE LA SALUD * VIOLENCIA SIMBÓLICA

ABSTRACT

This article analyzes the symbolic violence to the light of knowledge, attitudes and practices that health staff have about the care of middle-aged women experiencing menopause. At the methodological level, it was proposed an exploratory-descriptive study. The method used was KAP survey (Knowledge, Attitudes and Practices). This approach identified as an important finding, the need to promote a paradigm shift regarding the traditional view of menstrual cessation and how your approach has been devised.

KEYWORDS: WOMEN * MEDIAN AGE * MENOPAUSE $*$ HEALTH PERSONNEL $*$ SYMBOLIC VIOLENCE

Instituto de Investigaciones Psicológicas (IIP) de la Universidad de Costa Rica (UCR).

andres.castillo@ucr.ac.cr

Hospital San Francisco de Asís, Caja Costarricense de Seguro Social, Costa Rica.

ivanniacb@yahoo.com 


\section{INTRODUCCIÓN}

En el presente artículo se analizarán los conocimientos, actitudes y prácticas del personal de salud del Área de Salud de Montes de Oca, respecto a la atención de mujeres en edad mediana que experimentan la menopausia y cómo dichas variables se vinculan con el ejercicio de la violencia simbólica, ello en tanto se parte de la comprensión de las y los proveedores de servicios en salud como sujetos culturales que eventualmente pueden transmitir $y / 0$ ejercer distintas manifestaciones de la violencia simbólica dentro de los espacios de consulta. Justamente, este tipo de violencia es considerada una de las manifestaciones de la violencia social más sutil y difícil de identificar, ya que opera en las esferas comunicativas de la cultura, en sus signos y símbolos, de modo que se presenta en espacios de representación y comunicación social, aspecto que ha promovido su naturalización tanto por quienes la reciben como por quienes la ejercen (Plaza: 2007).

Esta condición de la violencia simbólica conduce a que todos los seres humanos estemos expuestos a ella, en nuestra calidad de sujetos culturales.

Partiendo de tal reconocimiento, el presente análisis se sustenta en una postura género sensitiva que incorpora elementos del enfoque de derechos humanos y del enfoque generacional, con miras a contextualizar diversas formas de violencia simbólica que experimentan las mujeres en edad mediana, relacionadas con su proceso menopáusico. Más aún, la incorporación de estos enfoques contribuye al desarrollo de nuevas líneas de investigación feminista que brinden insumos para crear una propuesta de trabajo, en torno al abordaje que debe darse a la vivencia de la menopausia de mujeres en edad mediana. En este marco, la menopausia será entendida no solo desde su significación biomédica, sino primordialmente a partir de todas aquellas significaciones psicosociales que le representan como un evento vital natural, colmado de una gran cantidad de significaciones que abarcan aspectos biológicos, identitarios, culturales, familiares, comunitarios, entre otros.
Asimismo, la menopausia se visualiza en el contexto general de la edad mediana, ya que es precisamente dicho plano generacional el que brinda un marco de significación mayor a este $y$ a otros procesos que se experimentan en esta etapa de desarrollo. La edad mediana, en síntesis, agrega nuevos sentidos a la vivencia de las mujeres que experimentan la menopausia, ya que se encuentra caracterizada por diversos elementos que pueden facilitar u obstaculizar la manera en que se viva el cese de la menstruación.

Es así que, partiendo de una conceptualización más amplia de la menopausia de aquella a la que tradicionalmente ha recurrido la ciencia médica, surgió la necesidad de indagar con el personal de salud, sus conocimientos, actitudes y prácticas en relación con las mujeres en edad mediana que experimentan la menopausia, esto con el objetivo de vincular estas tres variables con el ejercicio de la violencia simbólica y así identificar formas alternativas de mejorar la atención en salud de las mujeres en edad mediana que incluyan posturas integrales $y$ género sensitivas, respetuosas de los derechos humanos de este grupo poblacional.

Tal acercamiento adquiere mayor relevancia, en tanto, según el censo nacional de población realizado durante el año 2000 , se estima que existen alrededor de 437664 mujeres con edades entre los 35 y los 54 años; $y 265$ 049 mujeres con edades entre los 45 y los 64 años; mostrando un cambio importante en el perfil epidemiológico del país, cuya tendencia al envejecimiento impacta directamente en la oferta y en la demanda de los servicios de salud (Instituto Nacional de Estadísticas y Censos, 2002), lo cual motiva a que un número mayor de mujeres consulte respecto a la vivencia de su cese menstrual.

En aras de garantizar la comprensión de la temática en cuestión, en los siguientes apartados se expone el marco conceptual que brinda sustento teórico al estudio. Posteriormente, se retoman los aspectos implicados en el diseño metodológico y seguido a ello, se presentan los principales resultados con su respectiva discusión. Por último, se plantean las conclusiones $y$ recomendaciones de la investigación, como parte de las cuales se destaca la necesidad de 
aportar a las ciencias de la salud otros marcos referenciales desde los cuales cuestionar $y$ ampliar sus posicionamientos respecto a la menopausia $y$ a las mujeres en edad mediana que le experimentan; sin obviar que dicho proceso requiere una ruptura paradigmática respecto a la visión tradicional del cese menstrual y a la manera en que su abordaje ha sido concebido.

\section{MARCO TEÓRICO-CONCEPTUAL}

En los siguientes apartados se describen los ejes teórico-conceptuales que respaldan la investigación, entre ellos, la edad mediana femenina como periodo generacional en el que acontece el cese menstrual, los diferentes enfoques (biomédico y psicosocial) en la significación y atención de la menopausia y por último, las manifestaciones de la violencia simbólica, subrayando cómo ésta se vincula con la atención en salud de las mujeres que experimentan la menopausia.

\section{COMPRENDIENDO LA EDAD MEDIANA FEMENINA COMO CONTEXTO VITAL DE LA MENOPAUSIA}

El presente estudio considera que el cese menstrual es un proceso enmarcado en la edad mediana femenina, el cual varía para cada mujer según la sociedad en que se encuentre inmersa. Aún y cuando no es posible circunscribir dicha etapa vital a una dimensión cronológica estricta, al existir multiplicidad de definiciones de la edad mediana, existentes en la literatura, se torna necesario delimitarle - con estrictos fines metodológicos- como aquél período situado entre los 45 y los 59 años de edad.

La edad mediana es conceptualizada por algunas autoras como "edad madura o madurez" (López, 1991 y Carreño, 1999), "edad crítica" (López, 1991) y "crisis de la mitad de la vida" (Villarreal, 1996). Aunado a ello, se distingue como "una fase diferenciada del ciclo vital con peso y características propias, que no debe ser confundida con la vejez" (López, 1991: 202). De igual modo, se le ha recalcado como una transición vital normal que suele acompañarse de estrés (López, 1991) en razón de las múltiples y rápidas transformaciones corporales, familiares, laborales, sociales e identitarias que introduce (Breen, 1999) y que no se reducen a la menopausia ni al "nido vacío" (Baruch y Brooks-Gunn citadas por López, 1991). En palabras de esta última autora:

... en la edad madura o 'crítica' la mujer experimenta diversos y profundos cambios en su cuerpo, en su familia, en su medio social, en sus tareas. Estos cambios atañen a su identidad femenina socialmente configurada e inseparablemente ligada al desempeño de roles de distintas configuraciones familiares como [pareja,] madre, hija, ama de casa $y$ a las exigencias de nuestra cultura de mantenerse joven, físicamente atractiva y sexualmente deseable. También en esta época se producen, con frecuencia, cambios en los roles laborales [...] El grado en que estos cambios son percibidos como pérdidas irremediables, que generan síntomas psicofísicos, o como cambios vitalmente positivos que fortalecen el desarrollo personal, parece depender más de las definiciones y prescripciones culturales para la mujer y sus roles, de las variables de personalidad y de las circunstancias sociales y familiares que de imperativos biológicos (López, 1991: 200).

Con base en los aportes que brinda esta contextualización, resulta posible visualizar la menopausia como un cambio más en la vida femenina que se entreteje de forma compleja con toda una serie de pasajes y transiciones psicosociales mayores. En dicho marco, el grado en que todo este conglomerado de eventos afecta o no el desenvolvimiento intrapersonal e interpersonal de la mujer, deberá ser comprendido siempre de manera particular. Al respecto, Breen (1999) recuerda que "no existe una sola experiencia esencial de las mujeres en edad mediana [...] ningún mensaje es válido para todas las mujeres [...] las diferencias de clase, raza, cultura y orientación sexual pueden tener como resultado experiencias de vida radicalmente diferentes" (Breen, 1999: 31). 
Cabe agregar que el abordaje de los procesos vitales femeninos ha estado tradicionalmente carente de una perspectiva generacional-contextual, pues ha obviado las características de la edad mediana, homogenizando experiencias, creando síntomas comunes a todas las mujeres, negando su diversidad e irrespetando la relatividad cultural y vivencial, entre otros múltiples sesgos de género.

\section{ENFOQUES EN LA SIGNIFICACIÓN Y ATENCIÓN DE LA MENOPAUSIA}

Si bien, la perspectiva biomédica ha sobresalido como el enfoque primordial $y$ tradicional tanto en la conceptualización como en la atención de la menopausia, en este acápite se partirá del enfoque de género para analizar los planteamientos, tanto de la aproximación biomédica como de la lectura psicosocial, ello con el propósito de develar esquemas de información, actitudes, mitos, valoraciones, así como, conceptos construidos $y$ perpetrados alrededor de la menopausia y sus significados — personales y colectivos-, además de la respuesta del sector salud ante esta experiencia.

En lo que respecta al enfoque biomédico, este se caracteriza por el abordaje de las señales y "síntomas" de la menopausia y/o procesos asociados, a partir de tratamientos hormonales o químicos u otro tipo de prescripción que coincida con la medicalización y patologización de dicho proceso vital. Más concretamente, este arraigado posicionamiento circunscribe la comprensión del cese menstrual a un orden fisiológico preponderante (Dos Reis y Rafael: 1999), que acentúa el carácter patológico de la menopausia (Kaufert, 1982) por medio del énfasis en lo problemático y en la validación de símbolos metafóricos negativos por excelencia (Hunter, 1995 y Mitchinson, 2006). Desde esta lógica, dicho enfoque promueve una lectura individual no solo patologizante de tal experiencia de vida, sino que también promueve su medicalización (Ferguson y Parry, 1998; Mitchinson, 2006).

En palabras de Ferguson y Parry (1998: 8):

...aparte de fracasar al clarificar los riesgos y las opciones de la menopausia para la mujer, otra debilidad del modelo biomédico es que la representa falsamente como una condición universalmente problemática para la mayoría de las mujeres (sino para todas), desde el momento en que la menopausia inicia y hasta la muerte ${ }^{1}$.

El enfoque tradicional biomédico también sobresale por desconocer el derecho de las mujeres a controlar sus propios cuerpos, otorgándole al personal médico el poder de decisión (Kaufert, 1982) y demandando ante este, una postura de total sumisión y obediencia por parte de la mujer. Siguiendo a esta misma autora, en la literatura médica sobresale con destacada claridad la aceptación implícita y explícita de que en la relación médico(a)-paciente, la mujer asume un rol pasivo, excepto por su responsabilidad de solicitar atención y de describir detalladamente sus síntomas. De este modo, las apreciaciones de las mujeres respecto a aquello que les afecta $y$ necesitan, pasan a un segundo plano y no gozan del mismo poder decisorio en la definición de la atención por recibir.

En estrecha relación con esta solapada anulación de derechos de la mujer que experimenta la menopausia, el modelo tradicional ha legitimado la metáfora del descontrol (Ferguson y Parry, 1998) para sugerir que en este proceso vital no se tiene potestad sobre las propias acciones ni sobre el cuerpo. De este modo, desde muchos frentes simultáneos se sostiene la imagen de un sujeto femenino débil, frágil, enfermo, presa de los caprichos de sus hormonas $y$ necesitado de una respuesta 'salvadora' externa que ordene el 'caos' interno.

En contraste, esta investigación reconoce la existencia de otra serie de significados y definiciones socioculturales que circulan en el imaginario popular, los cuales tienden a calificar como "menopausia" a muchos otros cambios físicos, emocionales o sociales experimentados por la mujer en su edad mediana.

Integrando esta otra gama de representaciones, el enfoque psicosocial conceptualiza la menopausia como un proceso natural y polidimensional enmarcado en la edad mediana,

$1 \quad$ Traducción libre del inglés al español por parte de los autores. 
la cual explica y adiciona otra serie de cambios psíquicos y sociales asociados a la identidad femenina $y$ al rol cultural tradicionalmente asignado — desde la ideología patriarcal— a las mujeres que experimentan el cese menstrual (Lock, 1995; Hunter, 1995; Uberoi y Badahur, 2001). Dicha postura, busca un acercamiento a la comprensión de la menopausia a partir de su reconocimiento como construcción sociocultural, es decir, no considera los cambios fisiológicos y corporales como eje o foco principal de análisis, sino que más bien cuestiona muchas de las tergiversaciones y sesgos de género a los que ha conducido tal priorización, develando así, el papel de la cultura en la construcción de imágenes, vivencias y representaciones de la menopausia que pueden significarle de manera positiva $o$ negativa, reproduciendo muchas veces, en este último caso, el ejercicio de la violencia simbólica.

Justamente, este tipo de violencia puede manifestarse a través de sesgos de género, desde los cuales se patologizan, descalifican, sobredimensionan y descontextualizan los cambios asociados al cese menstrual, además de generalizar, homogenizar y validar una imagen deteriorante de este hecho vital (López, 1991; Rodríguez, 1999; Rojas, Balmaceda y Rojas, 2007).

Partiendo de los alcances del enfoque psicosocial, en el proceso de visibilización y deconstrucción de la violencia simbólica respecto a procesos vitales femeninos como la menopausia, resulta imprescindible recurrir a enfoques críticos y no reduccionistas, como el enfoque de género, el generacional contextual y el enfoque de derechos humanos; último que contempla todos aquellos derechos de las mujeres en edad mediana que experimentan la menopausia, tales como el derecho a la información, a la participación en su propia atención, a la toma de decisiones informadas, al tratamiento consentido $y$ a la salud sexual $y$ reproductiva. Asimismo, promueve un abordaje no solo individual, sino también familiar y comunal de la menopausia desde una perspectiva de desarrollo que le contextualice en el período de la edad mediana (Arilha, Hakkert, Andino, Díaz y Leonard, 2003). De igual modo, propicia una atención género sensitiva de las mujeres consultantes, que reconoce la importancia de no generalizar, patologizar ni homogenizar sus experiencias, como tampoco fomentar un ejercicio del poder autoritario en los servicios brindados. Por último, apoya la no descalificación, minimización u otra modalidad de violencia simbólica dirigida a mujeres que afrontan su cese menstrual (Flores y Sagot, 2006; Rojas, Balmaceda y Rojas, 2007).

En síntesis, la atención de la menopausia desde el enfoque de derechos humanos es aquella que a partir del eje de la dignidad humana, se enriquece con los aportes tanto del enfoque generacional-contextual, como de los provenientes de la perspectiva de género. Por lo anterior, el concepto de menopausia empleado en este trabajo investigativo, no coincide en términos estrictos con la comprensión biológica de la menopausia como el acto preciso de desaparición del flujo menstrual, pues incorpora su representación colectiva como proceso significativo de cambio en la vida femenina. Tal acercamiento parte de lo socialmente construido, esto es, de la sobredimensión de la menopausia para propiciar su relectura, enmarcándole justamente en el período vital de la edad mediana.

Sin embargo, para garantizar una significación y atención de la menopausia respetuosa de los derechos humanos de las mujeres en edad mediana, es vital reflexionar con mayor detenimiento en torno a las modalidades en que opera la violencia simbólica y cuáles son algunas de sus manifestaciones posibles en los servicios de atención en salud.

3. LAS ESFERAS DE LA VIOLENCIA SIMBÓLICA Y SU VINCULACIÓN CON LA ATENCIÓN EN SALUD DE MUJERES QUE EXPERIMENTAN LA MENOPAUSIA

Se entiende por violencia simbólica, aquel tipo de violencia "amortiguada, insensible e invisible para sus propias víctimas, que se ejerce esencialmente a través de los caminos puramente simbólicos de la comunicación, del conocimiento o, en último término, del sentimiento" (Bourdieu, 2000: 12). Siguiendo a Zúñiga (2004):

... la violencia simbólica es un término acuñado para designar la imposición de significados válidos y legítimos en 
la sociedad, vinculados al ejercicio del poder y a la autoridad, de manera que el conjunto de representaciones sociales resultantes son asumidas como naturales por mujeres $y$ hombres mediante procesos de socialización genérica que se llevan a cabo por las distintas instituciones de la estructura social, entre ellas, la educación, la familia, la religión y hasta la ciencia (2004: 44-45).

En el caso específico de esta investigación, la violencia simbólica será analizada a partir de determinados sesgos de género: androcentrismo ${ }^{2}$, sexismo ${ }^{3}$, doble estándar ${ }^{4}$ o descontextualización (Rojas, Balmaceda y Rojas, 2007) reproducidos por el personal de salud; mismos que serán entendidos como todas aquellas valoraciones subjetivas desde las cuales se patologizan, descalifican, sobredimensionan $y$ descontextualizan los cambios asociados al cese menstrual, además de generalizar, homogenizar $y$ validar una imagen deteriorante de este hecho vital. Incluyen además aquellas inclinaciones, afectos y juicios de valor que fomentan un ejercicio del poder autoritario en la relación con las mujeres consultantes y que reproducen o legitiman símbolos y signos que denotan representaciones despectivas y devaluadoras de la condición femenina en razón del cese menstrual (López,

2 Se define androcentrismo como una lectura patriarcal del mundo que se caracteriza por "la formulación hegemónica del sexo masculino, heterosexual, [y] adulto" en la cual "se establece el arquetipo viril como referente" para definir lo humano (Rodríguez, 1999: 293-295).

Por sexismo se entiende "la discriminación relacionada con la pertenencia a un sexo determinado, [...] es aplicable, tanto a hombres como a mujeres" (González, 2004: 11), aunque por las condiciones históricas que caracterizan a nuestra cultura, el sexo femenino es el que mayormente se ha visto afectado por esta forma de exclusión.

Doble estándar hace referencia a la valoración desigual $y / 0$ asimétrica de alguna cosa, actividad $u$ objeto de acuerdo con el sexo y género de la persona que la realice, por ejemplo, la desvalorización o invisibilización del conocimiento y saber femenino en actividades consideradas no tradicionales para mujeres (Rojas, Balmaceda y Rojas, 2007).
1991; Rodríguez, 1999; Rojas, Balmaceda y Rojas, 2007).

Una vez reseñado el concepto de violencia simbólica, resulta importante resaltar algunos ejemplos de cómo dicho concepto puede manifestarse dentro de los servicios de atención en salud. En este sentido, una de las formas más reveladoras o evidentes es sugerida por el valor simbólico que posee el saber médico en la significación de los cuerpos y los procesos vitales femeninos. Así, en el caso particular de la menopausia, Charlton (2003: 111) afirma que el personal médico considera la menopausia como una enfermedad, la cual es tratada por medio de la "aplicación de la terapia hormonal sustitutiva, los exámenes de osteoporosis, mamografía, $y$ tranquilizantes, entre otros". Por su parte, Coria, Freixas y Covas (2005) plantean que la menopausia es utilizada por la medicina para justificar cualquier queja, problema o malestar externado por las mujeres en edad mediana, mientras que Villareal (citada por Madden e Hidalgo, 2004: 5) argumenta que "la explicación médica biologista presenta a la menopausia como una enfermedad $y$ pone especial énfasis en la sintomatología y en los malestares que las mujeres experimentan, no en ellas como personas".

Es así que resulta notorio cómo la violencia simbólica en sus diversas manifestaciones ya sea por medio del androcentrismo, el sexismo o cualquier otro mecanismo-, es vislumbrada dentro de los servicios de salud siempre que se busque homologar las experiencias femeninas o se decida arbitrariamente sobre sus cuerpos o procesos vitales. También se torna evidente cuando las mujeres juegan un rol pasivo $y$ de obediencia ante la prescripción médica, la cual no es analizada, discutida o negociada; asumiendo una actitud que acepta paradójicamente el tratamiento prescrito solo porque lo receta el/la profesional en medicina en calidad de figura de gran valor social y reconocimiento simbólico.

Asimismo, otros mitos reproducidos por el personal de salud respecto al cese menstrual se vinculan con la supuesta relación entre menopausia y problemas emocionales (Mitchinson, 2006), pérdida o dificultades en la respuesta sexual femenina (Chinchilla, 2005), etapa crítica y periodo de declive (Moncraz, 1999), entre otros, que a su vez pueden presen- 
tarse de forma indirecta, encubierta y solapada en el discurso manifiesto de dicha población (Madden e Hidalgo, 2004).

Teniendo en consideración este panorama, podría concluirse que para impactar sobre la violencia simbólica en la prestación de servicios en salud, es imperante la presencia de un recurso humano sensible, que conozca y utilice de forma positiva el valor simbólico de sus significaciones y que comprenda las diferentes necesidades de salud en la edad mediana femenina, dependiendo incluso de la configuración de la edad, etnia y estatus socioeconómico de las mujeres consultantes.

\section{MÉTODO}

\section{DISEÑO}

La presente investigación se concibe como un estudio cuantitativo exploratorio-descriptivo, no experimental, transversal de una sola medición, de carácter censal, basado en un paradigma postpositivista ${ }^{5}$ que integra una postura epistemológica ${ }^{6}$ feminista (Harding, 1987), coincidente con un paradigma transformativo (Hernández, Fernández y Baptista, 2006b). Su carácter cuantitativo se explica en tanto la recolección de los datos se fundamenta en la medición numérica de las variables estudiadas (conocimientos, actitudes y prácticas) a partir de procedimientos estandarizados (Hernández, Fernández y Baptista, 2006a), complementados por un posterior análisis estadístico de la información recabada. Partiendo de esta categorización, también se clasifica

5 Positivismo: corriente del pensamiento, según la cual todas las 'cosas' o fenómenos que estudian las ciencias son medibles, a la vez que propone la aplicación del método científico de las ciencias naturales al estudio de los fenómenos sociales. Como precursores de esta corriente en las ciencias sociales destacan Augusto Comte y Emile Durkheim (Hernández, Fernández y Baptista, 2006a: 4).

6 Postura epistemológica: "conjunto de suposiciones de carácter filosófico de las que nos valemos para aproximarnos a la búsqueda del conocimiento, la noción que compartimos de la realidad $y$ de verdad, $y$ el papel que cumple el[la] investigador[a] en esta búsqueda del conocimiento, al igual que la manera como asumimos al sujeto estudiado" (Páramo y Otálvaro, 2006: 3). como transversal o transeccional de una sola medición, ya que la recolección de los datos se realizó en un momento único (Hernández, Fernández y Baptista, 2006a).

En lo que respecta a su profundidad, propósito $y$ alcances, el estudio se caracteriza como una aproximación, tanto exploratoria como descriptiva (Barrantes, 2007; Hernández, Fernández y Baptista, 2006a). Exploratoria en tanto indaga un tema poco estudiado, desde nuevas aproximaciones metodológicas, tales como la encuesta CAP (conocimientos, actitudes y prácticas) y su utilidad en el marco de un acercamiento género-sensitivo.Asimismo, constituye una investigación descriptiva por cuanto busca especificar características, dimensiones y tendencias (Hernández, Fernández y Baptista, 2006a) de las variables estudiadas.

Finalmente $y$ en concordancia con los fundamentos teórico-metodológicos de las estadísticas de género (Hedman, Perucci y Sundström, 1996), el presente estudio parte de la premisa de que la inclusión de lo numéricoestadístico puede ser conceptualizada como una estrategia política dirigida a impactar en aquellas autoridades institucionales que requieren resultados más medibles y cuantificables para la toma de decisiones vinculadas con la promoción de la salud integral femenina.

\section{POBLACIÓN}

La investigación es considerada como un censo, debido que pretendió estudiar a una población entera (Kerlinger y Howard, 2002), en este caso a 68 funcionarios(as) que, para el segundo semestre del año 2009, conformaban el personal de salud del Área de Salud de Montes de Oca del Programa de Atención Integral de Salud (PAIS) y brindaban algún tipo de atención directa a mujeres que experimentan la menopausia. Sin embargo, solo fue posible contar con una muestra de 36 participantes ${ }^{7}$, entre ellos: cuatro asistentes técnicos(as) en

$7 \quad$ Al caracterizarse la presente investigación como un estudio de participación voluntaria, la tasa de respuesta se vio altamente afectada, alcanzando únicamente el 52,9\% del total de funcionarios(as) del Área de Salud de Montes de Oca del Programa de Atención Integral de Salud (PAIS). 
atención primaria (ATAP's), seis auxiliares de registros médicos $\left(\operatorname{REMES}^{8}\right)$, siete auxiliares de enfermería, once médicos(as), seis integrantes del equipo de apoyo y dos cuyo dato no pudo ser registrado. Dicho personal es procedente de los quince EBAIS correspondientes a los núcleos de Mercedes, Vargas Araya, Barrio Pinto, Lourdes y San Rafael/San Ramón (De la Unión).

\section{VARIABLES DE ESTUDIO}

En la presente investigación, las unidades de análisis, entendidas como "los sujetos, objetos, sucesos o comunidades de estudio" (Hernández, Fernández y Baptista, 2006a: 236), están constituidas por los conocimientos, las actitudes $y$ las prácticas del personal de salud respecto a la atención de mujeres en edad mediana consultantes que experimentan la menopausia. A continuación se describen dichas variables.

A. CONOCIMIENTOS: el conocimiento se define como "el cuerpo de información poseído por una persona o, por extensión, por un grupo de personas o una cultura" (Reber citado por Pozo, 2003: 44). De esta forma, el conocer aludiría también a la capacidad que poseen los seres humanos de adquirir nueva información o conceptos, quedando en evidencia otra de sus características fundamentales, la cual refiere a su carácter individual o grupal, ya que la adquisición de un nuevo esquema cognitivo de información puede ser asimilado, tanto de manera personal como colectiva.

Ahora bien, partiendo de la definición anterior, el presente estudio desagrega tal unidad de análisis en las siguientes clasificaciones:

$\diamond \quad$ Conocimientos sobre menopausia: entendidos como aquellos esquemas de información (cognitivos) y conceptos que posee el personal de salud respecto al cese menstrual, en sus procesos tanto

$8 \quad$ Si bien, los/las asistentes de registros médicos no brindan atención técnica directa a ningún usuario(a), sí participan activamente en la atención de las personas consultantes y en dicho contacto se encuentran en la posibilidad de emitir criterios respecto a los temas de interés de la presente investigación. biológicos, como bioquímicos, fisiológicos, anatómicos, psicológicos, generacionales, sociales y culturales.

$\diamond \quad$ Conocimientos en torno a la atención en salud de mujeres que experimentan la menopausia: entendidos como aquellos esquemas de información (cognitivos) y conceptos que posee el personal de salud respecto a la prestación de servicios y a la atención, en el primer nivel de la Caja Costarricense de Seguro Social (CCSS), de mujeres en edad mediana que experimentan la menopausia, ello tanto desde el enfoque biomédico como desde las premisas básicas del enfoque de derechos humanos, el enfoque generacional contextual y la perspectiva de género.

B. ACTITUDES: esta variable es conceptualizada como todas aquellas percepciones, afectos, resistencias o disposiciones personales o grupales de carácter evaluativo, en relación con un tema o fenómeno social en específico; considerando para este estudio particular, las actitudes del personal de salud frente a la experiencia menopáusica de mujeres en edad mediana y respecto al abordaje de este proceso vital en el marco de los servicios de atención primaria.

En palabras de Ajzen (2001: 28), el término actitud "representa una evaluación resumida de un objeto psicológico capturado en dimensiones de atributos tales como bueno-malo, dañino-beneficioso, placentero-displacentero $y$ agradable-desagradable" ${ }^{\text {. Así, el modelo en }}$ cuestión reconoce que los juicios evaluativos frente a una situación, condición u objeto son el resultado de procesos cognitivos, a la vez que responden a afectos $y$ a valoraciones subjetivas conscientes e inconscientes, todos los cuales interactúan con relativa independencia, fuerza y ambivalencia según las características personales y contextuales ${ }^{10}$.

$9 \quad$ Traducción libre del inglés al español por parte de los autores.

10 Tal postura se enmarca en el modelo de expectativavalor (Fishbein y Ajzen, 1975; Ajzen y Fishbein, 2008), el cual sintetiza y complementa una serie de aproximaciones teóricas previas al concepto de actitud, provenientes de la psicología social norteamericana. 
Por su parte, Kahle y Oskamp (citados por Hernández, Fernández y Baptista, 2006a: 146), definen actitud como "una tendencia o predisposición a evaluar de cierta manera un objeto o un símbolo de este objeto", en consecuencia, coincide con una dimensión subjetiva valorativa, que se expresa a través de afectos, tendencias, inclinaciones, predisposiciones, mitos, estereotipos y juicios de valor (prejuicios).

C. PRÁCTICAS: las prácticas pueden ser conceptualizadas como conductas o manifestaciones conductuales habituales $y / 0$ rutinarias. Al respecto, cabe precisar que de acuerdo con Skinner (citado por Quintana, 1985: 400), la conducta es "lo que el organismo hace, o de forma más rigurosa, lo que otro organismo observa que hace [...] aquella parte del funcionamiento del organismo que consiste en actuar o en relacionarse con el mundo exterior". Para el caso específico de la presente investigación, las prácticas son concebidas como "las maneras en las cuales se demuestran los conocimientos $y$ las actitudes a través de acciones" (Kaliyaperumal, 2004: 7), en este caso, los comportamientos habituales o rutinarios que el personal de salud cotidianamente realiza en la atención de mujeres en edad mediana que experimentan la menopausia.

\section{INSTRUMENTO}

Se utilizó el método de la encuesta CAP (conocimientos, actitudes y prácticas), mediante un cuestionario autoadministrado conformado por 7 preguntas abiertas y 114 preguntas cerradas (divididas en cuatro escalas según variables y dimensiones estudiadas), así como, reactivos de pregunta en escalas tipo Likert y de diferencial semántico (Hernández, Fernández y Baptista, 2006a).

El instrumento utilizado se caracteriza por ser un cuestionario pre-codificado, el cual fue sometido a un riguroso proceso de validación, mismo que incluyó una prueba piloto, la revisión por parte de un grupo de personas expertas y las respectivas pruebas estadísticas para evaluar la consistencia interna y garantizar su validez y confiabilidad.
En el marco de la presente investigación, resulta oportuno mencionar que las encuestas CAP son conceptualizadas como una evidencia de base para la planificación, definición y evaluación de iniciativas de cambio de políticas institucionales, comunicación y movilización social en áreas temáticas específicas (World Health Organization, 2008).

\section{ESTRATEGIA DE ANÁLISIS}

En relación con el proceso de registro de la información, se ordenaron los datos pre-codificados y se codificaron las preguntas abiertas, procesando ambos por medio de una base de datos diseñada con el programa SPSS. En este procedimiento, cada participante fue registrado(a) inicialmente con un número de caso para poder realizar posteriormente, la etapa de análisis de la información.

En cuanto al análisis, se recurrió a estadísticas descriptivas como parte de las cuales se emplearon distribuciones de frecuencias, cruces de variables, elaboración de medidas de tendencia central y de variabilidad, tablas, cuadros y gráficas que resumieron los datos (Hernández, Fernández y Baptista, 2006a). Asimismo, se prestó especial atención a la identificación de aquellos grados o niveles de consenso en que el enfoque tradicional biomédico de comprensión $y$ atención de la menopausia se ve reflejado en los conocimientos, actitudes y prácticas del personal de salud participante en el estudio. En contraste, también se analizó la distribución porcentual en que otros enfoques como el generacional contextual, el de derechos humanos $y$ la perspectiva de género se hacen presentes desde las cogniciones, valoraciones y acciones de la población en estudio.

A este análisis cuantitativo de los datos, se suma un análisis género-sensitivo dirigido a integrar una interpretación contextual, política y sociocultural de los datos "duros", con miras a articular un posicionamiento crítico desde la perspectiva de género, el enfoque de derechos humanos y el enfoque generacional-contextual.

\section{CRITERIOS DE VALIDEZ Y CONFIABILIDAD}

Para certificar la fiabilidad del instrumento, se realizaron una serie de análisis 
estadísticos con el fin de asegurar la consistencia interna del mismo, entre dichos análisis sobresale el empleo del Alfa de Cronbach como una de las medidas de consistencia interna más utilizadas en el paquete estadístico SPSS. Al respecto, los Alfa de Cronbach reportados en el trabajo de campo en las distintas escalas del instrumento se ubicaron entre el .64 y el .96.

Por otro lado, para asegurar la validez de contenido de dicho instrumento, se construyeron y contrastaron las preguntas o ítems elaborados con las variables y dimensiones esbozadas en el marco conceptual. Asimismo, con el objetivo de certificar la validez de expertos(as), una vez construida la primera versión del cuestionario se realizó una sesión de trabajo, en la cual especialistas en los temas de investigación cuantitativa, violencia y atención en salud analizaron la estructura del instrumento, su diseño, la redacción y ubicación de los ítems, entre otros puntos, ello con la finalidad de depurar el cuestionario de acuerdo con su experticia. Posteriormente, para garantizar la validez de constructo se realizó un análisis de factores por medio del paquete estadístico SPSS, el cual contribuyó a reafirmar la correlación existente entre los ítems de cada escala, así como, la correspondencia teórica de estos con las variables a investigar.

Finalmente, se realizó una prueba piloto del cuestionario a 60 funcionarios y funcionarias de las Áreas de Salud de Curridabat, San Juan, San Diego y Concepción. Dichas áreas forman parte del PAIS y presentan características similares y/o comparables con las de la población meta del estudio. Producto de esta aplicación piloto, se realizó un nuevo proceso de eliminación de ítems de acuerdo con los resultados obtenidos en los análisis de confiabilidad $y$ de consistencia interna efectuados; asimismo, se modificó la estructura del instrumento conforme a las lecciones aprendidas y recomendaciones sugeridas por las personas participantes.

\section{RESULTADOS}

La descripción de resultados que se presenta a continuación, se organiza en los siguientes acápites: características generales de la población, conocimientos en torno a la menopausia (desde los enfoques biomédico y psicosocial), conocimientos en torno a la atención de mujeres en edad mediana que experimentan la menopausia (atención biomédica y atención con enfoque de derechos humanos), actitudes respecto a este grupo etario y prácticas dirigidas a mujeres en edad mediana que atraviesan el cese menstrual. En concordancia con dicho esquema de organización, se reportan frecuencias y porcentajes que reflejan el nivel de consenso en las respuestas emitidas por las personas participantes. Con tal objetivo, los resultados se agrupan con base a la siguiente clasificación:

a. Consenso alto: porcentaje de respuesta igual o mayor al $70 \%$ del total de respuestas.

b. Consenso intermedio: porcentaje de respuesta entre el 50\% y $69 \%$ del total de respuestas.

c. Consenso bajo: porcentaje de respuesta entre el $0 \%$ y $49 \%$ del total de respuestas.

Posteriormente, estos niveles de consenso se analizaron según la presencia de sesgos de género que evidencian violencia simbólica en la atención de mujeres en edad mediana consultantes o en la significación de los procesos femeninos que atraviesan.

\section{1) CARACTERÍSTICAS GENERALES DE LA POBLACIÓN}

En su mayoría la población participante se caracteriza por estar constituida en un $66,7 \%$ por mujeres y un $27,8 \%$ por hombres. A su vez, el $72,2 \%$ de las personas que respondieron el instrumento de recolección de datos tenía entre 25 y 39 años de edad. Por otra parte, la universidad completa sobresalió como el último grado académico del 52,8\% del personal de salud censado. Asimismo, en el estudio predominó la participación de profesionales en medicina, quienes constituyeron el 30,6\% de la población total. El 55,6\% de las personas participantes tenían entre 5 y menos de 10 de trabajar en el PAIS, en la disciplina reportada. Finalmente, el núcleo con mayor representatividad dentro del estudio fue Vargas Araya, cuyo personal de salud constituyó un $25,0 \%$ de las personas participantes. 


\section{2) CONOCIMIENTOS EN TORNO A LA MENOPAUSIA}

\section{DIMENSIÓN BIOMÉDICA}

En lo que respecta a los resultados obtenidos sobre los conocimientos biomédicos en torno a la menopausia, destacan algunas áreas del conocimiento biomédico en las que más de un $70 \%$ del personal de salud participante coincidió en sus respuestas, a diferencia de algunos temas en los que se observó mayor variabilidad $y$ otros en los que se encontró menor consenso. En esta última categoría es posible citar la asociación causal entre menopausia y disminución del deseo sexual en la mujer o la caracterización del cese menstrual como una falla hormonal deficitaria. Entre las áreas temáticas en las que se observó mayor uniformidad en las respuestas del personal de salud, destacan la consideración de la menopausia como un proceso natural, en tanto el 100\% de las personas respondientes lo consideró como tal, así como, la caracterización del síndrome climatérico como un conjunto de signos y síntomas asociados con la disminución de los niveles de estrógeno en la mujer. Otras áreas del conocimiento biomédico en las que también se manifestó un consenso significativo, fueron aquellas referidas al papel preponderante $y$ privilegiado del/la profesional de medicina en la clasificación como "menopáusicos" o no, de síntomas expresados por la mujer consultante.

Asimismo, más de la mitad de las personas participantes coincidieron con postulados tradicionalmente defendidos en torno a la menopausia, tales como: la asociación directa de esta con la pérdida de la función ovárica, la consecuente atrofia de los órganos reproductivos que conlleva $y$ su identificación certera una vez transcurrido un año desde la última menstruación.

En relación con los signos y síntomas asociados a la menopausia y al climaterio, cabe resaltar cuatro signos y síntomas principales a saber: ausencia o cese menstrual, calores y bochornos, cambios en el estado de ánimo y problemas asociados con la respuesta sexual femenina, entre otros que se detallan en el siguiente cuadro. 


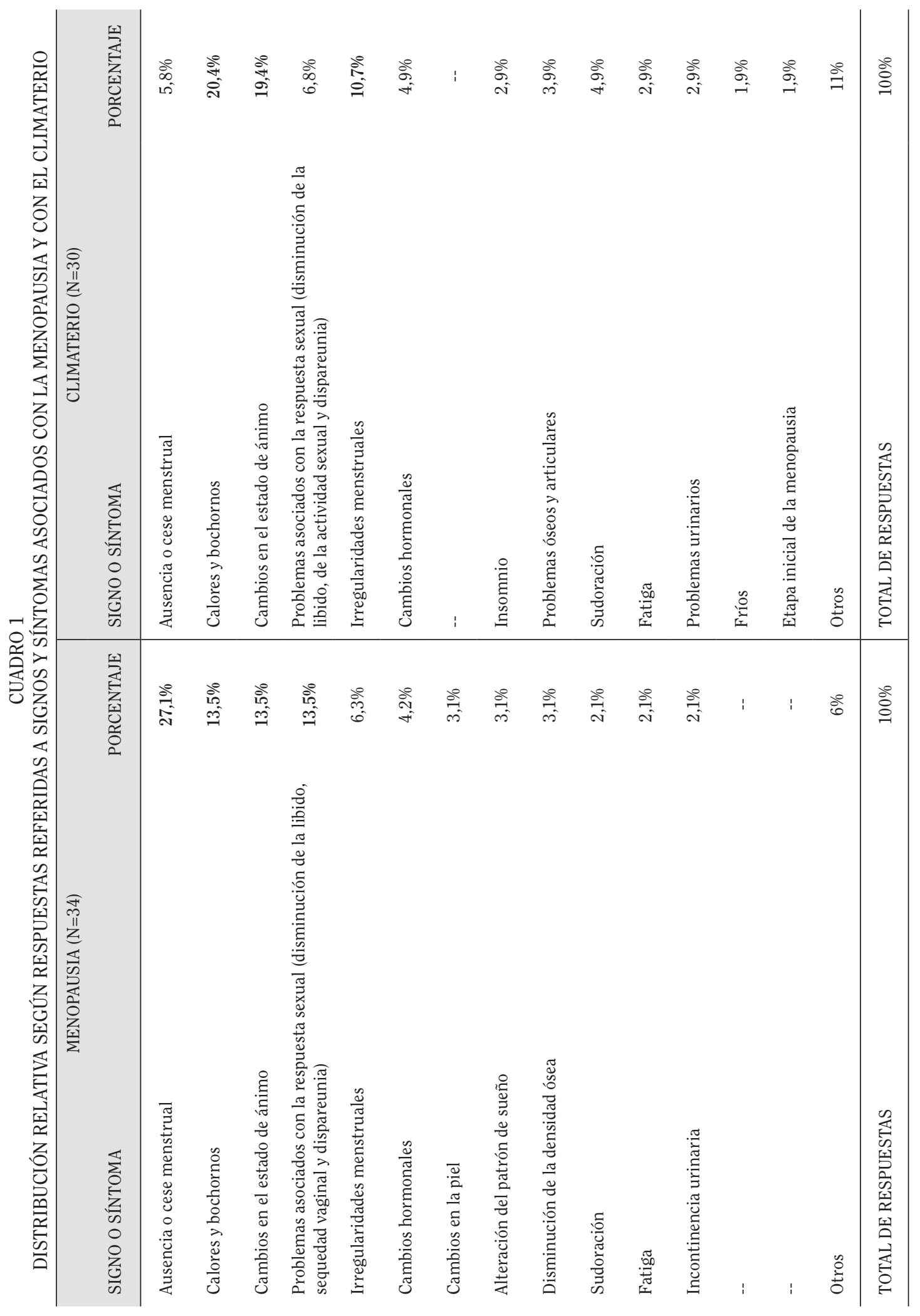

Rev. Ciencias Sociales Universidad de Costa Rica, 140: 47-72 / 2013 (II). (ISSN: 0482-5276) 
Según lo evidencia el cuadro anterior, los calores y bochornos, los cambios en el estado de ánimo y los problemas asociados con la respuesta sexual femenina, constituyen en igual medida señales tanto de la menopausia como del climaterio, esto de acuerdo al criterio del personal de salud estudiado. Más aún, los signos y síntomas señalados como indicadores de ambos procesos femeninos solo se diferencian en la frecuencia con que fueron referidos.

De esta manera, parece perfilarse un esquema cognitivo que no representa a la mujer sin período menstrual con imágenes de disfrute sexual, estabilidad emocional ni bienestar corporal, atribuyendo más bien los cambios en el estado emocional de la mujer directamente a procesos de origen fisiológico reconocido - como el climaterio $y$ la menopausia $-y$ no a procesos vitales como la edad mediana; última que constituye, sin embargo, el principal correlato causal y contextual que eventualmente impulsa tales cambios.

\section{DIMENSIÓN PSICOSOCIAL}

En cuanto a esta dimensión, sobresale que a diferencia de la dimensión de conocimientos biomédicos en torno a la menopausia, presentó el mayor número de preguntas abiertas no respondidas. Así, se aprecia que al menos un cuarto de la población participante omitió definir la edad mediana y tampoco citó derechos de las mujeres que atraviesan dicho período en lo referente a su atención en salud. Otra particularidad de los resultados obtenidos en la escala respectiva de preguntas cerradas, es que las personas participantes solo coincidieron en un nivel intermedio al afirmar que la menopausia consiste en un proceso de desarrollo normal; mientras que en los demás esquemas de información explorados privó la heterogeneidad de criterios, evidenciándose una considerable dispersión de los datos recogidos entre las posibilidades de respuesta de la escala.

Se detectó mayor desconocimiento en el ítem que indaga si la edad mediana constituye el período vital en el que acontecen la menopausia $y$ el climaterio. Este resultado, aunado a la no respuesta en la pregunta sobre definición de la edad mediana por parte de un cuarto del personal de salud censado, sugiere que dicho período vital no constituye un contenido temático básico en la formación de los(as) participantes del Área de Salud de Montes de Oca.

Respecto a los ítems sobre el papel de la cultura en la significación y vivencia de la menopausia, se logró identificar gran variabilidad de posturas entre las personas respondientes, pues no se obtuvo consenso alto entre la población censada. Para algunas personas, la cultura marca diferencias en el significado y experiencia del cese menstrual, para otras no aporta criterios diferenciales y en un último caso, hay quienes opinan que no existe certeza en torno al papel que juega o no la cultura en relación con la menopausia.

En lo que respecta a la capacitación y/o educación que han recibido los(as) participantes en torno a diferentes temáticas relacionadas con sus labores dentro del Área de Salud, en la encuesta CAP aplicada, el 69,4\% del personal participante señalo no haber recibido ninún tipo de capacitación en torno al marco conceptual de derechos humanos. No obstante, sobresalió un 30,6\% que indicó contar con formación en el tema de derechos. Por otro lado, en torno al enfoque de género en la prestación de servicios, se observó que el $83,3 \%$ de las personas respondientes no están capacitadas en el tema, únicamente el 16,7\% de funcionarios(as) mencionaron estarlo.

En lo concerniente a la definición de edad mediana y señalamiento de derechos de las mujeres de edad mediana en la atención en salud, se registraron porcentajes notables de la categoría no respuesta. Así, en la conceptualización de edad mediana, un $25 \%$ de las personas participantes no contestó, mientras que para la pregunta referida a derechos en atención de las mujeres en edad mediana, la no respuesta ascendió a un 27,8\%.

Entre las definiciones de edad mediana destacan diferentes conceptualizaciones. Un primer grupo la delimita con base en rangos de edad, los cuales variaron entre un límite inferior de 30 años, hasta un límite superior de 69 años, con gran diversidad en los intervalos planteados. Un segundo grupo resaltó no solo el carácter evolutivo de dicho período vital, sino también su asociación con un desarrollo integral superior de la mujer, descrito por medio de calificativos como "madurez", "sabiduría", "integración”, entre otros. Finalmente, una última agrupación de definiciones destaca la 
edad mediana como una época de cambios especialmente vinculados con un correlato hormonal y físico, como parte del cual sobresale la alusión directa al climaterio, a la menopausia $y$ al envejecimiento.

Los resultados que develan los conocimientos del personal de salud censado respecto a los derechos de las mujeres en edad mediana en la atención en salud, dan cuenta que el derecho a la información y el derecho a la atención de calidad fueron los más señalados, abarcando un $44,7 \%$ del total de respuestas. Una visión global de la frecuencia con que fueron indicados estos $y$ otros derechos es presentada en el cuadro 2.

CUADRO 2

DISTRIBUCIÓN ABSOLUTA Y RELATIVA SEGÚN DERECHOS DE MUJERES EN EDAD MEDIANA EN LA ATENCIÓN EN SALUD IDENTIFICADOS POR LOS Y LAS PARTICIPANTES $(\mathrm{N}=26)$

\begin{tabular}{lcc}
\hline DERECHO & FRECUENCIA & PORCENTAJE \\
\hline Derecho a la información & 11 & $23,4 \%$ \\
Atención de calidad & 10 & $21,3 \%$ \\
Derechos iguales a los demás & 8 & $17 \%$ \\
Derecho a la atención médica & 6 & $12,8 \%$ \\
Derecho a la atención integral & 4 & $8,5 \%$ \\
Derecho a decidir & 3 & $6,4 \%$ \\
Educación en salud & 3 & $6,4 \%$ \\
Respeto de la particularidad & 2 & $4,3 \%$ \\
\hline TOTAL & 47 & $100 \%$ \\
\hline
\end{tabular}

De acuerdo con el cuadro anterior, también se identifica que para un $17 \%$ de las personas participantes, los derechos en salud de las mujeres en edad mediana no difieren de los derechos de otros grupos etarios, intergenéricos o intragenéricos.

3) CONOCIMIENTOS EN TORNO A LA ATENCIÓN EN SALUD DE MUJERES DE EDAD MEDIANA QUE EXPERIMENTAN LA MENOPAUSIA

\section{ATENCIÓN CON ENFOQUE BIOMÉDICO}

En relación con esta escala, es importante mencionar que el nivel de consenso en las respuestas emitidas se ubica mayormente en el nivel bajo. Aunque algunos ítems obtuvieron consenso intermedio y solo un caso en específico obtuvo consenso alto, dicha variabilidad impide hablar de tendencias claramente acentuadas en el comportamiento de los datos.

Con un porcentaje mayor al $70 \%$ del total de las respuestas, 28 personas adujeron estar nada de acuerdo con la afirmación de que la educación en salud no es tan importante en la atención del climaterio y la menopausia.

Por otra parte, únicamente 2 ítems alcanzaron un consenso de respuesta intermedio, registrándose desacuerdo con que la terapia de reemplazo hormonal pueda revertir los efectos del envejecimiento, así como con el hecho de que todas las mujeres que experimentan la menopausia presenten las mismas necesidades de atención en salud, atribuyéndoles un 52,8\% $y$ un $61,1 \%$ respectivamente.

Respecto a la terapia de reemplazo hormonal (THR), prevalece un consenso del 33,3\% que se manifestó muy de acuerdo con que los beneficios de dicha terapia son mayores que sus efectos secundarios, por otra parte, el 44,4\% estuvo nada de acuerdo con que la THR proteja a las mujeres contra el cáncer de mama y otro $44 \%$ se mostró a favor (muy de acuerdo) de brindar información a las mujeres consultantes respecto a terapias alternativas a la THR. No obstante, es interesante contrastar estos datos con el hecho de que un 33,3\% de las personas censadas estuvieron totalmente de acuerdo o muy de acuerdo con que la THR mejora considerablemente el estado de ánimo de la mujer.

Aunado a ello, se evidencia un consenso del $44,4 \%$ que dijo estar nada de acuerdo con que la atención médica especializada sea suficiente para que las mujeres que experimen$\tan$ la menopausia puedan mejorar su vivencia sexual; asimismo, un 30,6\% estuvo poco o nada de acuerdo con que la menopausia sea tratada como un problema de salud. Finalmente, un $41,7 \%$ se posicionó nada de acuerdo con que la atención de mujeres que experimentan la menopausia no siempre requiera un diagnóstico previo de sus necesidades en salud. 


\section{ATENCIÓN CON ENFOQUE DE DERECHOS HUMANOS}

En lo que respecta a los conocimientos que posee la población censada en torno a la atención con enfoque de derechos humanos de mujeres de edad mediana que experimentan la menopausia, se pudo identificar que en cuanto a la atención de la edad mediana femenina, el $83,3 \%$ no ha recibido capacitación en dicha área. La atención del climaterio y la menopausia obtuvo porcentajes similares al anterior, en tanto un $75 \%$ del total de las respuestas reflejó la falta de formación en el tema, mientras que el restante 25\% afirmó haber sido capacitado principalmente entre el año 2000 y el 2005.

De acuerdo a los aspectos que cada funcionario(a) considera importante explorar $y$ considerar en la atención de mujeres en edad mediana, sobresalen las condiciones de salud física y prevención de enfermedades con un $41,7 \%$ de consenso en las respuestas, los aspectos psicológicos y emocionales con un $36,1 \%$ $y$ el interés por la salud sexual de las mujeres consultantes con un $22,2 \%$. Por otra parte, el $19,5 \%$ fue atribuido tanto a los estilos de vida saludables y las relaciones de vida con $11,2 \%$ y $8,3 \%$ respectivamente.

\section{4) ACTITUDES RESPECTO A MUJERES EN EDAD MEDIANA QUE EXPERIMENTAN LA MENOPAUSIA}

En relación con las actitudes del personal de salud respecto a las mujeres en edad mediana que experimentan la menopausia, sobresale que la mayoría de respuestas a las preguntas cerradas alcanzaron un consenso intermedio.

En este sentido, se aprecia que la mayor parte del personal de salud censado no apoyó esquemas valorativos como los siguientes: que debido al ocio las mujeres en edad mediana se concentran más en sus padecimientos, que la mayoría de los cambios emocionales en mujeres mayores de 45 años se debe a la menopausia, que el atractivo físico de la mujer se pierde con la llegada del climaterio, que los rasgos femeninos disminuyen con la reducción de estrógenos, que al llegar a la menopausia se experimenta un rápido deterioro físico o que la menopausia marca el fin del deseo sexual de la mujer. El 55,6\% de las personas respondientes también consideró que el climaterio y la menopausia constituyen temas que no requieren un abordaje médico especializado por parte de la ginecología.

Por otro lado, el 69,4\% estuvo nada de acuerdo con que la llegada del climaterio marca la pérdida del atractivo físico de la mujer y con esa misma posición, el 63,9\% se opuso a que la menopausia marca el fin del deseo sexual de la mujer.

Aunado a ello, cabe señalar que de todos los mitos explorados, solo en dos de ellos - justamente aquellos que fueron redactados en sentido contrario a la dirección tradicional del mito ${ }^{11}$ — poco más de la mitad de las personas respondientes expresaron poco acuerdo respecto a la afirmación de que las mujeres se vuelven más productivas con la menopausia $(55,6 \%)$ y se manifestaron nada de acuerdo respecto a la idea de que las mujeres se tornan más femeninas con la ausencia de la menstruación $(52,8 \%)$.

Por último, la población censada mostró una posición más dividida al consultársele si después de la menopausia las mujeres se interesan más que antes en las relaciones sexuales, ante lo cual el 44,4\% estuvo nada de acuerdo y frente a la afirmación de que es difícil entender a las mujeres que experimentan el climaterio $y$ la menopausia, el 44,4\% estuvo poco de acuerdo. En lo que concierne al diferencial semántico, resulta oportuno señalar que un número significativo de respuestas se ubicó en un punto neutral entre los pares de adjetivos posibles para calificar la menopausia, así los porcentajes de respuesta que optaron por no caracterizar dicho proceso vital en ninguno de los polos disponibles variaron entre un $27,8 \%$ y un $55,6 \%$, con un valor promedio de $38,6 \%$.

Más allá de esta actitud de reserva, desde la cual muchas personas participantes decidieron no calificar abiertamente a la menopausia, es posible distinguir algunos ítems en los que al menos un cuarto de las respuestas registradas le ubica cercana a algún polo, ya sea negativo o positivo. Como se puntualiza en el cuadro 3 -en el cual se

11 Por ejemplo, en lugar de anotar "Con la menopausia las mujeres se vuelven menos productivas", se redactó "Con la menopausia las mujeres se vuelven más productivas". 
suprime el valor intermedio predominante-, tal es el caso de las relaciones fácil-difícil, actividad-pasividad, gracia-desgracia, en las cuales se observan los porcentajes más altos de consenso de las respuestas no centralizadas en el valor medio de la escala.

CUADRO 3

DISTRIBUCIÓN RELATIVA SEGÚN ÍTEMS DE LA ESCALA DE DIFERENCIAL SEMÁNTICO

CON PORCENTAJE DE RESPUESTA IGUAL O MAYOR AL 25\% DEL TOTAL DE RESPUESTAS BRINDADAS POR EL PERSONAL DE SALUD CENSADO

\begin{tabular}{|c|c|c|c|c|c|c|c|}
\hline ÍTEM & ADJETIVO & 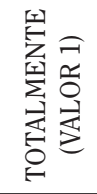 & 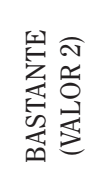 & 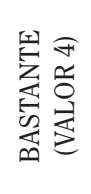 & 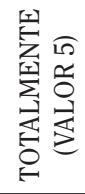 & ADJETIVO & $\mathrm{N}$ \\
\hline 19.1 & Salud & $19,4 \%$ & $30,6 \%$ & $13,9 \%$ & $0 \%$ & Enfermedad & 35 \\
\hline 19.3 & Cómodo & $16,7 \%$ & $16,7 \%$ & $30,6 \%$ & $0 \%$ & Incómodo & 34 \\
\hline 19.6 & Fácil & $8,3 \%$ & $11,1 \%$ & $38,9 \%$ & $5,6 \%$ & Difícil & 34 \\
\hline 19.7 & Seguridad & $11,1 \%$ & $27,8 \%$ & $5,6 \%$ & $2,8 \%$ & Peligro & 33 \\
\hline 19.9 & Libertad & $22,2 \%$ & $27,8 \%$ & $2,8 \%$ & $2,8 \%$ & Encierro & 34 \\
\hline 19.10 & Tranquilidad & $19,4 \%$ & $25 \%$ & $16,7 \%$ & $2,8 \%$ & Temor & 34 \\
\hline 19.11 & Estabilidad & $19,4 \%$ & $27,8 \%$ & $8,3 \%$ & $5,6 \%$ & Inestabilidad & 34 \\
\hline 19.12 & Cordura & $30,6 \%$ & $25 \%$ & $8,3 \%$ & $2,8 \%$ & Locura & 34 \\
\hline 19.13 & Gracia & $16,7 \%$ & $33,3 \%$ & $0 \%$ & $0 \%$ & Desgracia & 33 \\
\hline 19.17 & Independencia & $30,6 \%$ & $27,8 \%$ & $2,8 \%$ & $0 \%$ & Dependencia & 34 \\
\hline 19.18 & Actividad & $25 \%$ & $33,3 \%$ & $5,6 \%$ & $2,8 \%$ & Pasividad & 34 \\
\hline 19.19 & Aceptación & $27,8 \%$ & $25 \%$ & $8,3 \%$ & $0 \%$ & Rechazo & 34 \\
\hline
\end{tabular}

De acuerdo con esta serie de respuestas, la menopausia fue valorada en síntesis como bastante cercana tanto a la salud, la seguridad, la libertad, la tranquilidad, la estabilidad, la gracia y la actividad; mientras sobresale como mucho más cercana a la cordura, la independencia y la aceptación. En contraste, también fue calificada como bastante cercana a lo difícil y a lo incómodo. Destaca igualmente que ninguna persona participante le calificó como una desgracia o ni siquiera próxima a ella.

Estas aproximaciones y esquemas evaluativos se clarifican aún más mediante la sumatoria de los porcentajes registrados en las dos posibilidades de respuesta cercanas al polo positivo y aquellas afines al polo negativo de los pares de adjetivos que integraron la escala del diferencial semántico, cuyos resultados dejan entrever una marcada tendencia de respuesta hacia los polos positivos de cada par de adjetivos, con excepción de las asociaciones fácildifícil y cómodo-incómodo. En esta misma situación de porcentajes de respuesta similares se encuentra la relación ganancia-pérdida, desde la cual un $25 \%$ de las valoraciones registradas calificaron la menopausia como una ganancia, en tanto un 22,2\% le evaluó más bien como una pérdida.

Valga destacar que aquellos pares evaluativos que obtuvieron porcentajes menores de respuesta en los polos positivo y negativo, a saber, positivo-negativo y ganancia-pérdida, fueron justamente los que alcanzaron los porcentajes más altos de distribución en el punto central de cada díada. Así, un 55,6\% no consideró la menopausia como positiva ni como negativa, mientras un $50 \%$ no la valoró como ganancia ni como pérdida.

A modo de cierre, se aprecia que desde las valoraciones manifiestas compartidas por el personal de salud participante, la menopausia se acerca - casi en la totalidad de su experiencia - a constituirse como una vivencia favorable o positiva, con excepción de su 
consideración desfavorable al estimarse que no propicia un incremento en la productividad de la mujer, como tampoco un aumento de su feminidad. En esta misma línea valorativa, se identificó consenso respecto a que la menopausia consiste en un proceso bastante o muy difícil, así como relativamente incómodo.

\section{5) PRÁCTICAS DIRIGIDAS A MUJERES EN EDAD MEDIANA QUE EXPERIMENTAN LA MENOPAUSIA}

En lo que respecta a esta variable, ninguna de las respuestas obtuvo consenso alto entre el personal de salud censado. En cuanto al consenso intermedio, destacaron prácticas relacionadas con la escucha atenta, donde el 66,7\% señaló hacer esto siempre, al igual que si mira directamente a la mujer consultante mientras habla con ella, acción que obtuvo un $61,1 \%$ de consenso. Del mismo modo, el 69,4\% afirmó que siempre hace comentarios que le ayuden a ver su proceso como algo normal, no como una enfermedad; a su vez, el 50\% mencionó que siempre le hace saber su derecho a aceptar o no aceptar las recomendaciones que le brinde, además de que un 58,3\% argumentó demostrar paciencia al escuchar su relato. Asimismo, un $52,8 \%$ afirmó nunca sentir aburrimiento al escuchar a la mujer y un 69,4\% expresó tampoco disgustarse cuando la usuaria no le explica bien lo que siente.

Adicionalmente, como prácticas que no se aplican a las funciones que desarrollan dentro del Área de Salud, la mayoría de personas participantes que respondieron la escala destacó la prescripción de THR y el hecho de brindar información sobre otras modalidades de apoyo no hormonal, con un $61,1 \%$ y un $50 \%$ de consenso respectivamente.

\section{DISCUSIÓN}

VIOLENCIA SIMBÓLICA Y SESGOS DE GÉNERO IDENTIFICADOS EN LA CONCEPTUALIZACIÓN, VALORACIÓN Y ATENCIÓN DE LA MENOPAUSIA

Tras la descripción de datos reseñada en las líneas anteriores, no solo se colige que en cada una de las variables de estudio, las respuestas aportadas por la población estudia- da fueron diversas, caracterizándose por su heterogeneidad $y$ variable grado de consenso, sino que también impresiona un comportamiento general de los datos orientado a reflejar una valoración positiva de la experiencia de la menopausia por parte del personal de salud, así como, un elevado auto reporte de prácticas que no violentan a las mujeres consultantes y más bien, respetan los derechos humanos de estas, sin embargo, reconociendo el carácter solapado de la violencia simbólica y sus manifestaciones, el presente apartado se propone profundizar aún más en los resultados descritos, en aras de dilucidar sus articulaciones con eventuales sesgos de género y equivalencias de sentido conexas.

Tal y como se ha referido anteriormente, la medicalización constituye un fenómeno complejo, que a lo largo de la historia ha legitimado la equivalencia "menopausia=enfermedad" (Ferguson y Parry, 1998). Así, su presencia puede identificarse no solo en prácticas, actitudes y conocimientos que validan abiertamente el cese menstrual como un problema de salud, sino también en abordajes centrados en el plano individual, desde los cuales se aprueba la prescripción de tratamientos hormonales con el objetivo de disminuir la gama de síntomas y signos asociados al cese menstrual, entre otras manifestaciones muchas veces más sutiles y ambivalentes.

Partiendo de dichas consideraciones, la descripción de resultados no permite reconocer tendencias de respuesta claramente definidas o uniformes en relación con dicha analogía, sino que por el contrario, en lo que el personal de salud participante quiso dar a conocer, sobresalen criterios divididos respecto a si la menopausia coincide o no con atributos y características asociadas con patología.

No obstante, a la luz de un acercamiento género sensitivo se logra apreciar cómo la categorización de la menopausia en calidad de síndrome, falla hormonal deficitaria, pérdida de la función ovárica y atrofia de los órganos reproductivos, emplea términos técnicos que coinciden en representar la ausencia menstrual como un evento deteriorante y por consiguiente, más cercano a un problema y a una pérdida, que a una ganancia (Ferguson y Parry, 1998; 
Bulbeck, 2001; Mitchinson, 2006). Sin embargo, este fundamento teórico y análisis deconstructivo, no se ve claramente reflejado en los datos recopilados, por cuanto la valencia negativa que tales adjetivos denotan parece no ser reconocida abiertamente por parte del personal de salud cuando este tiende a denominar la menopausia como un proceso natural y positivo.

Retomando con mayor detalle esta aparente contradicción, cabe acotar que un $69,4 \%$ de las personas participantes coincidió en que dicho hecho vital es un proceso de desarrollo normal, tan natural como la primera menstruación o el nacimiento, asimismo el 69,4\% afirmó que con sus comentarios ayuda a las mujeres a ver este proceso como algo normal, no como una enfermedad. En lo que respecta a la relación salud-enfermedad, indagada en la escala de diferencial semántico, solo un 13,9\%, calificó el cese menstrual como bastante cercano al polo de la enfermedad. Finalmente, un $61,2 \%$ del personal censado se expresó poco de acuerdo o nada de acuerdo con que la menopausia sea tratada como un problema de salud.

Esta interrelación de respuestas demuestra, hasta este punto, consistencia en la exposición de conocimientos $y$ actitudes favorables con la enunciación del cese menstrual en calidad de proceso normal y natural. Así, en la serie de reactivos que examinaron esta equivalencia, poco más de la mitad de los(as) funcionarios(as) de salud que completaron el cuestionario no calificó explícitamente la menopausia como una enfermedad; en contraste con un número menor de participantes que sí la caracterizó de tal forma.

No obstante, la referida inclinación al empleo de términos coincidentes con patología y esta recién señalada tendencia a negar la menopausia como un problema de salud, emergen, sin lugar a dudas, como elementos contradictorios y en este sentido, motivan el necesario cuestionamiento de ¿por qué emplear conceptos médicos para dar cuenta de procesos que discursivamente se señalan como naturales? Más aún, cabe precisar que dicha discrepancia, se confirma al analizar los signos y síntomas atribuidos por las personas participantes, tanto a la menopausia como al climaterio, donde predomina la referencia de problemas físicos (calores, bochornos, irre- gularidades menstruales), emocionales (cambios en estado de ánimo) y sexuales (disminución de la libido, sequedad vaginal, dispareunia), aunados a otros cambios que no se inscriben en una esfera positiva, sino más bien de deterioro corporal.

De esta forma, el hecho de que la mayoría de la población censada continúe catalogando la menopausia como un proceso normal - no como una enfermedad-, a pesar de que también enumere síntomas que dan cuenta de pato$\operatorname{logía}^{12}$, visibiliza una escisión discursiva desde la cual se sostienen dos planteamientos opuestos entre sí, cuya contradicción se disocia al punto de que quien lo enuncia, parece no percatarse de la incompatibilidad de ambos planteamientos.

Integrando los resultados vinculados con conocimientos en torno a la atención del cese menstrual, se advierte que más de la mitad de la población censada asocia la terapia de reemplazo hormonal con cierta mejoría en la salud de las mujeres en mediana edad, a la vez que se muestra a favor de una atención que trascienda la lectura biomédica tradicional.

Ahora bien, en un intento por vincular los hallazgos presentados con la violencia simbólica, se perfila que a través de términos empleados para describir la menopausia -tales como síndrome, falla, pérdida, atrofia, entre otros-, aunados a la equivalencia "terapia de reemplazo hormonal-mejoría en la salud de la mujer" y la no implicación de diversos funcionarios(as) en acciones relacionadas con la educación en salud en torno a la menopausia, se visualizan rasgos coincidentes con la medicalización como sesgo que tiende a representar el cese menstrual en calidad de evento médico. Al respecto, destaca que el lenguaje de la ciencia impone de manera indirecta y encubierta (Madden e Hidalgo, 2004), significados que patologizan y negativizan, pero que a la vez naturalizan y normalizan el cese menstrual. Ello permite subrayar que las vías de expresión de la violencia simbólica en la atención en salud no solamente deben buscarse en lo evidentemente manifiesto, sino también en la carga simbólica de lo dado, asumido e instituido, que se transmite con lo dicho, pero también con lo no dicho y actuado, con las contradicciones y ambivalencias desapercibidas.

12 Referidos al cese menstrual y no asociados a enfermedades crónicas comunes en la edad mediana. 
En síntesis, cabe precisar que la tarea de identificar los sesgos y manifestaciones de violencia simbólica no resulta sencilla ni espontánea, especialmente debido a su carácter solapado y a la arraigada naturalización de sus representaciones (Bourdieu, 2000).

Prosiguiendo con este análisis, es primordial resaltar que el personal de salud participante destaca los cambios en el estado de ánimo como uno de los signos principales de la menopausia Asimismo, al consultar sobre los signos y señales del climaterio, igualmente sobresalen los cambios en el estado de ánimo con un 19,4\% del total de respuestas.

La contestación de ambas interrogantes no solamente vislumbra una asociación entre la ausencia de menstruación y el desequilibrio emocional, sino también una homologación entre los signos y señales de la menopausia $y$ del climaterio, lo cual conlleva a pensar en la escasa diferenciación que realiza el personal de salud censado en relación con ambos conceptos y sus características. En este sentido, dicha homologación podría explicarse en la escasa o nula capacitación que ha recibido el personal de salud en torno a la atención del climaterio y la menopausia, ya que el $75 \%$ de las personas participantes respondió no haber recibido ningún tipo de preparación o adiestramiento en esta temática.

Por otra parte, respecto al ítem que indaga si la menopausia causa cuadros depresivos $y$ problemas emocionales diversos, un $72,2 \%$ de las personas participantes consideró como verdadera dicha afirmación. Tal apreciación coincide con la señalada tendencia a atribuir a la menopausia alteraciones en el estado de ánimo femenino y podría ser explicada por la presencia solapada del mito cultural de que las mujeres se tornan confusas, irascibles e inestables a causa del cese menstrual (Losoviz, 2000).

En este marco, a pesar del aparente esfuerzo discursivo del personal de salud estudiado por responder los ítems de acuerdo a lo socialmente deseable, emergen una serie de sesgos de género que visualizan la presencia de manifestaciones de la violencia simbólica en torno a la equivalencia causal reportada entre la menopausia y la existencia de problemas emocionales.
Por su parte, una esfera actitudinal y cognitiva en la que se observan sesgos de género con mayor claridad es aquella referida a la relación entre menopausia y respuesta sexual femenina. Al respecto, un $83,3 \%$ de las personas participantes se posicionó poco de acuerdo o nada de acuerdo con la idea de que después de la menopausia las mujeres se interesan más en las relaciones sexuales que antes. Lo anterior confirma que un amplio grupo de la población censada asocia la menopausia, ya sea con disminución del interés en el contacto sexual, con problemas varios en la respuesta sexual femenina o con ambos; a lo cual debe agregarse que, para algunas personas participantes, el cese menstrual conlleva el fin o el "cese" definitivo de la actividad sexual femenina.

Ahora bien, en relación con la visión que posee el personal de salud consultado en torno a la menopausia como una experiencia negativa, vuelven a presentarse una serie de contradicciones primordialmente al relacionar ítems del área de conocimiento con reactivos que miden actitudes en torno al cese menstrual.

Específicamente, destaca un porcentaje muy significativo de personas participantes para quienes la menopausia no debe ser considerada como un período crítico en la vida de la mujer o como el ocaso de su deseo sexual, su salud física o la disminución de su feminidad; no obstante, si comparamos estas respuestas con las respuestas emitidas en aquellos ítems en los cuales se invierte la valoración, es decir, aquellos en los que el mito no se encuentra redactado explícitamente en positivo, sino en negativo; se vuelve evidente cómo para un número importante del personal de salud estudiado, la menopausia constituye un proceso difícil en el cual la mujer es menos productiva $y$ menos femenina.

Por su parte, la idea distorsionada de que la menopausia es la antesala a la vejez, a la improductividad $y$ por ende a la muerte, puede explicarse a la luz de significaciones culturales - propias de un discurso dominante- que catalogan la ausencia menstrual como una "etapa crítica" o de "crisis", originando, tal como lo expresa Moncarz (1999), que la menopausia suela ser esperada como un momento de inflexión en la vida de las mujeres. 
Otro dato significativo se encuentra en las respuestas emitidas al ítem que indaga si el proceso de la menopausia es valorado negativamente en aquellas sociedades en las que se aprecia a la mujer, principalmente por su capacidad para tener hijos(as); ante lo cual, un 47,2\% respondió estar totalmente o muy de acuerdo. Tomando en consideración tal asociación, podría decirse que el personal de salud censado, avala o reconoce - al menos en el plano discursivo- como tradicionalmente la vivencia de la menopausia ha estado influenciada por la idea preconcebida de ocaso y pérdida, en aquellas sociedades en las cuales la reproducción es sinónimo de feminidad y emblema del ser mujer, valga acotar: en la mayoría de las sociedades occidentales actuales (Ferguson y Parry, 1998).

Finalmente, el análisis detallado de las contradicciones encontradas y la contrastación del discurso manifiesto contribuyen a identificar cómo en lo dicho por el personal de salud censado, subyace la idea de que la menopausia es una etapa improductiva en la vida de las mujeres que no promueve ni fortalece su feminidad. En consecuencia, sobresale como un período de declive, pero a la vez de emergencia, de confusiones emocionales $y$ de dificultades múltiples, todo lo cual reafirma la contradicción de calificativos positivos y negativos en la referencia del cese menstrual.

Como parte de este análisis, se torna imperante la problematización referida al papel que juega la atención que brinda el personal de salud, en la vivencia de la menopausia de mujeres en edad mediana consultantes. Investigaciones precedentes (Dos Reis y Rafael, 1999; Uncu, Alper, Ozdemir, Bilgel y Uncu, 2007; Vladislavovna, 2008) han demostrado que la figura del personal de salud - al constituirse en profesionales con una enaltecida valoración dentro del imaginario simbólico de nuestra sociedad-es determinante en la concepción que las mujeres en edad mediana consultantes poseen de su cuerpo y de los cambios físicos, emocionales, bioquímicos y sociales que experimentan durante esta etapa del ciclo vital.

Al respecto, un primer acercamiento a los resultados encontrados revela un inicial interés del personal de salud estudiado por reconocer - de manera general, más no específica- los derechos que las mujeres en edad mediana poseen al momento de ser atendidas. Este tipo de apreciaciones pueden ser sustentadas en la respuesta a los ítems referentes a conocimientos en torno a la atención, en los cuales el $97,2 \%$ de las personas participantes consideró estar totalmente de acuerdo o muy de acuerdo con que en la atención es especialmente importante escuchar a la mujer con calma e interés y un 91,6\% afirmó también estar totalmente de acuerdo o muy de acuerdo en que es importante explicarle a la mujer cuáles son sus derechos en salud en esta etapa de vida.

De esta forma, se deja entrever que los(as) funcionarios(as) participantes, reconocen en términos generales las características que debe tener una atención en salud sensible a los derechos humanos de las mujeres, a partir de la cual se promueva la escucha empática, el respeto por el relato de la mujer y la comprensión de sus emociones.

No obstante, comparando estos resultados con la respuesta a otros ítems, vuelven a presentarse una serie de contradicciones en relación con el tipo de atención que ofrece el personal de salud estudiado, las cuales evidencian la dificultad de integrar eficazmente en la práctica, un enfoque de derechos con las mujeres de edad mediana consultantes que atraviesan su cese menstrual. Así, la discrepancia entre las respuestas permite plantear dos hipótesis: la primera alude a que el enfoque de derechos se puede encontrar interiorizado en el personal de salud, como un discurso meramente cognitivo, que no conlleva directamente implicaciones prácticas. La segunda hipótesis, se relaciona con la validación implícita que el personal de salud realiza en relación con la dominación simbólica que ejerce al visualizar a las mujeres como usuarias, pacientes u objetos depositarios de su conocimiento y no como sujetos de derecho.

En este sentido, reconociendo que el "saber médico" constituye una de las visiones más representativas en la vida de las mujeres de edad mediana (López y Méndez, 2005), resulta imperante la realización de procesos de capacitación en torno al enfoque de derechos 
$y$ a sus implicaciones operativas en la atención en salud, en los cuales se transcienda la esfera cognitiva y se busque reflexionar e impactar en las actitudes y prácticas que ejecuta el personal de salud, esto con miras a un mayor reconocimiento de las particularidades genéricas en dicho período vital.

Ahora bien, al retomar un ítem que indaga si el personal de salud ha reflexionado, dentro de su práctica profesional, acerca de la importancia que posee su opinión para las mujeres en edad mediana que atiende, sobresale que solamente un 30,6\% expresó realizar siempre esta práctica; aspecto que revela cómo un alto porcentaje de personas participantes no parece asumir una postura crítica en torno a la relevancia que sus prácticas y su discurso ostentan en la vida de las mujeres consultantes. Tales resultados enfatizan, de manera indirecta, los postulados de Villareal (1996), cuando afirma que para la gran mayoría del personal en salud, la atención de mujeres en edad mediana que atraviesan la menopausia, es un proceso de rutina que no requiere de mayores procesos de introspección.

Prosiguiendo, este reconocimiento aparente de los derechos fundamentales de las mujeres consultantes, en contraposición con la idea de que solamente el o la profesional en salud se encuentra en capacidad de interpretar adecuadamente los signos y señales que la mujer presenta, puede interpretarse como una de las maneras en que la violencia simbólica se expresa en las prácticas del personal de salud estudiado. Más concretamente, dicho antagonismo puede traducirse en una forma solapada de silenciamiento y sometimiento de las experiencias femeninas, al priorizar el valor simbólico de presupuestos tradicionales en torno a la salud de las mujeres, tales como la reproducción de un rol jerárquico de poder, control y decisión por parte del personal de salud (Kaufert, 1982 y Bulbeck, 2001).

En síntesis, producto de la discusión anterior es posible identificar cómo las personas participantes en este estudio no demostraron una integración clara del enfoque de derechos en la atención en salud, como tampoco un reconocimiento explícito de la especificidad de estos para el caso de mujeres en edad mediana que atraviesan su cese menstrual.

La anterior conclusión refleja indicios de violencia simbólica y sesgos de género pues, a pesar de que se reporta que el derecho a la información y a una atención en salud oportuna $y$ atenta son las principales garantías que poseen las mujeres en edad mediana, cuando se contrastan estos derechos con las prácticas reportadas, no existe una clara relación entre lo que se consigna a nivel de conocimientos y lo que se ejecuta realmente. Más aún, como se ha indicado, los datos sugieren la legitimación de relaciones asimétricas entre el personal de salud y las mujeres consultantes.

El último aspecto por discutir, es la relación entre menopausia y significación cultural, debido al comportamiento manifiesto de los resultados obtenidos, en los cuales se reconoce la ausencia de capacitación en esta temática y el desconocimiento de la edad mediana como contexto vital en el cual se enmarca la ausencia de menstruación.

Sin embargo, el personal de salud estudiado a pesar de no poseer claridad conceptual en torno a la definición, características e implicaciones de la edad mediana, vislumbra discursivamente la relevancia de considerar la influencia de algunos elementos del contexto inmediato en las vivencias femeninas $y$ en las significaciones que las mujeres consultantes realicen de sus procesos vitales. Con ello, podrían sugerirse esquemas cognitivos eventualmente afines a la no sobredimensión del cese menstrual como el único y más importante cambio experimentado por las mujeres en edad mediana (López, 1991; Laurence y Weinhouse, 1994).

En resumen, producto del análisis efectuado, es posible afirmar que la edad mediana no resulta un término o concepto familiar ni cotidiano para el personal de salud censado. Por ello, adolecer de un posicionamiento contextual conceptual y operativamente claro - como parte del cual se reconozca la edad mediana en calidad de contexto vital que enmarca la menopausia- invisibiliza y obstaculiza la inclusión del enfoque generacional contextual en la atención en salud, a la vez que abre la posibilidad 
de incurrir en sesgos como la generalización en la atención a las mujeres de edad mediana consultantes. A la luz de estos descubrimientos, también resulta razonable sospechar que el no reconocimiento de la edad mediana como contexto general de desarrollo, impacta negativamente en la concepción de la menopausia que maneja el personal de salud, al no cuestionar y en consecuencia, reafirmar códigos de lectura biomédicos tradicionales. En otras palabras, en tanto no se validen nuevos marcos interpretativos que desliguen al cese menstrual de las coordenadas habituales desde las que ha sido significado, los esquemas cognitivos, actitudinales $y$ prácticos del personal de salud no contarán con nuevos alicientes a favor de su renovación y transformación.

\section{CONCLUSIONES}

Posterior a la descripción de resultados y a la discusión analítica esbozada con anterioridad, se reseñan a continuación de manera específica, las principales conclusiones de la presente investigación:

$\diamond \quad$ El reporte y la descripción de resultados - a nivel general- evidencia que el personal de salud posee una valoración positiva de la menopausia, al menos en el plano discursivo $y / 0$ manifiesto.

$\diamond \quad$ La presencia de contradicciones, ambivalencias, escisiones e incompatibilidades que emergen en el discurso manifiesto del personal de salud estudiado, contribuyen a identificar la presencia de diversas manifestaciones de violencia simbólica y sesgos de género presentes en sus conocimientos, actitudes y prácticas en torno a la menopausia $y$ a las mujeres en edad mediana; pues permiten el acercamiento a otras vías de expresión de la violencia simbólica que trascienden lo evidentemente discursivo, que emergen en la esfera simbólica de lo dado y de lo asumido $y$ que se transmiten por medio de mecanismos lingüísticos y expresiones no verbales vinculadas más con lo actitudinal $y$ con lo conductual que con lo cognitivo. $\diamond \quad$ De acuerdo con lo que la población estudiada quiso dar a conocer, puede concluirse que dicho personal de salud posee un alto nivel de conocimientos coincidentes con la comprensión de la menopausia como proceso biomédico, como parte de los cuales sobresale el uso de términos técnicos que le denotan como un síndrome, una falla hormonal deficitaria, la pérdida de la función ovárica o la atrofia de los órganos reproductivos femeninos, términos que coinciden en representar la ausencia de menstruación como un evento deteriorante, a pesar de que la totalidad de participantes considera que el cese menstrual es un evento normal y natural en la vida de las mujeres en edad mediana.

$\diamond \quad$ El personal de salud reporta mayoritariamente una valoración positiva del uso de la terapia de reemplazo hormonal al considerar que contribuye a mejorar la salud física y emocional de las mujeres en edad mediana. Dicha apreciación, evidencia un sesgo de medicalización en el abordaje del cese menstrual, mismo que escenifica la contradicción de medicalizar y patologizar aquello que se mencionó sano y natural.

$\diamond \quad$ Se percibe la homologación e indiferenciación de los términos climaterio y menopausia, en relación con sus signos y señales. Tal equivalencia, resalta la falta de capacitación y actualización en torno a dicha temática.

$\diamond \quad$ Es posible afirmar que existe una yuxtaposición de presupuestos del enfoque tradicional con presupuestos del enfoque psicosocial en la significación y en la atención de la menopausia, dado que cognitivamente el personal de salud reporta un discurso que deniega mitos y objeta sesgos en la atención de mujeres en edad mediana; empero, en muchas de sus prácticas $y$ actitudes se escenifican reduccionismos que patologizan al cese de la menstruación.

$\diamond \quad$ La mayoría del personal de salud estudiado dio a conocer una asociación entre 
la ausencia de menstruación y el desequilibrio emocional. Dicha asociación evidenció una serie de sesgos de género, referidos principalmente a la descontextualización de cambios emocionales, patologización emocional de la menopausia, interpretación biomédica de aspectos psicológicos asociados al cese menstrual - no a la edad mediana-y sobrevaloración de la TRH como coadyuvante ante los problemas emocionales "producidos por la menopausia".

El comportamiento de los datos descubre la presencia de altos contenidos de deseabilidad social en las respuestas del personal de salud estudiado, debido a que muchas de sus contestaciones pueden ser interpretadas como lo esperado a responder por un(a) funcionario(a) del sector salud. De esta manera, no es posible asegurar que lo afirmado en la esfera discursiva conlleve necesariamente implicaciones prácticas.

La atención a mujeres en edad mediana que experimentan la menopausia no es un tema prioritario en el primer nivel de atención en salud. Ello se ve reflejado en la falta de capacitación en torno a la misma $y$ en los tintes o visos reduccionistas con los cuales es abordado el cese menstrual por parte de diversos(as) proveedores(as) de servicios en salud.

Las personas participantes en la investigación no presentan claridad respecto a qué es la edad mediana y a su importancia en la vida de las mujeres que experimentan la menopausia. Dicho desconocimiento invisibiliza y obstaculiza la inclusión del enfoque generacional en la atención, así como de un marco interpretativo integral de la vivencia de las mujeres mayores de 45 años, en tanto no permite considerar la edad mediana como el contexto generacional que brinda una significación holista a la vivencia del cese menstrual.

$\diamond \quad$ Existe una dificultad real relacionada con la visibilización de la violencia simbólica en los conocimientos, actitudes y prácticas del personal de salud, pues dado el carácter consensuado, solapado $y$ amortiguado con el cual se naturaliza este tipo de violencia, resulta una tarea compleja, deconstruir los discursos manifiestos y latentes reportados por las personas participantes en el estudio.

$\diamond \quad$ El análisis de los resultados recopilados plantea la necesidad de aportarle a las ciencias de la salud otros marcos referenciales desde los cuales cuestionar y ampliar sus posicionamientos respecto a la menopausia y a las mujeres en edad mediana que le experimentan; sin obviar que dicho proceso requiere asimismo una ruptura paradigmática respecto a la visión tradicional del cese menstrual y a la manera en que su abordaje ha sido concebido.

\section{REFERENCIAS BIBLIOGRÁFICAS}

Ajzen, Icek. "Nature and operation of attitudes". Annual Review of Psychology 5. Estados Unidos: Annual Reviews, 2001: 27-58.

Ajzen, Icek y Fishbein, Martin. "Scaling and testing multiplicative combinations in the expectancy-value model of attitudes". Journal of Applied Social Psycholog 38. Estados Unidos: Wiley Periodicals, 2008: 2222-2247.

Arilha, Margareth; Hakkert, Ralph; Andino, Nieves; Díaz, Aida y Leonard, Daniel. Salud sexual y reproductiva de la mujer adulta mayor: un campo por explorar y evidenciar. UNFPA: Equipo de Apoyo Técnico para Latinoamérica y el Caribe, 2003.

Barrantes, Rodrigo. Investigación. Un camino al conocimiento. San José, Costa Rica: Editorial EUNED, 2007.

Breen, Mary. "Historias de mujeres en la madurez. Aprendiendo a escuchar, escuchando para aprender". La revolución de las canas. Reflexiones y experiencias sobre el envejecer de las mujeres. Gómez, Adriana (ed.). Santiago, Chile: Red de Salud de las Mujeres Latinoamericanas y del Caribe, 1999.

Bulbeck, Chilla. "Speaking menopause: intersections between Asian and Western 
medical discourses". Intersections: gender, history and culture in the Asian context 5. Australia: Murdoch University, 2001.

Bourdieu, Pierre. La dominación masculina. Barcelona: Editorial Anagrama, 2000.

Carreño, Dolly. "Madurez de la vida y género: una mirada sobre prácticas y realidades en el fin de siglo". La revolución de las canas. Reflexiones y experiencias sobre el envejecer de las mujeres. Gómez, Adriana (ed.). Santiago, Chile: Red de Salud de las Mujeres Latinoamericanas y del Caribe, 1999.

Charlton, Delfina. "Climaterio y menopausia, una mirada de género". Revista de Ciencias Sociales 3 (101). San José, Costa Rica: Universidad de Costa Rica, 2003: 107-112.

Chinchilla, Ivannia. "Feminidad y sexualidad femenina en la postmenopausia: aproximación psicoanalítica de las vivencias de dos mujeres de mediana edad del área metropolitana”. [Tesis de Licenciada en Psicología]. Universidad de Costa Rica, 2005.

Coria, Clara; Freixas, Anna y Covas, Susana. Los cambios en la vida de las mujeres. Buenos Aires, Argentina: Editorial Paidós, 2005.

Dos Reis, Ana Paula y Rafael, Meigie. "Envejecimiento femenino y menopausia. Un abordaje antropológico". La revolución de las canas. Reflexiones y experiencias sobre el envejecer de las mujeres. Gómez, Adriana (ed.). Santiago, Chile: Red de Salud de las Mujeres Latinoamericanas y del Caribe, 1999.

Ferguson, Susan y Parry, Carla. "Rewriting menopause: challenging the medical paradigm to reflect menopausal women's experiences". Frontiers: A Journal of Women's Studies 1. Estados Unidos: Arizona State University, 1998.

Fishbein, Martin y Ajzen, Icek. Belief, attitude, intention and behavior: an introduction to theory and research. Canada: AdisonWesley Publishing Company, 1975.
Flores, Daysi y Sagot, Montserrat. Lineamientos para promover el trabajo decente de jóvenes extrabajadores infantiles en zonas urbano-marginadas. San José, Costa Rica: Oficina Internacional del Trabajo y Programa Internacional para la Erradicación del Trabajo Infantil (OIT/IPEC), 2006.

González, Fernando. "Conocimientos, actitudes $y$ prácticas en salud sexual y reproductiva en jóvenes entre 14 y 25 años de edad de estratos 1 y 2 del SISBEN de un municipio del departamento de Cundinamarca". Revista Acta Colombiana de Psicología 12. Bogotá, Colombia: Universidad Católica de Colombia, 2004: 59-68.

Harding, Sandra. "¿Existe un método feminista?". Feminist and Methodology. Harding, Sandra (ed.). Indiana University Press, 1987.

Hedman, Birgitta; Perucci, Francesca y Sundström, Pehr. Estadisticas de Género: herramientas para el cambio. Statistics Sweden, 1996.

Hernández, Roberto; Fernández, Carlos y Baptista, Pilar. Metodología de la Investigación. México: Editorial Mc Graw Hill, 2006a.

Hernández, Roberto; Fernández, Carlos y Baptista, Pilar. "Historia de los enfoques cuantitativo, cualitativo y mixto". $C D$ anexo a Metodología de la Investigación. Cuarta edición. México: Editorial Mc Graw Hill, 2006b.

Hunter, Myra. La menopausia. ¿Cómo prevenir sus consecuencias físicas y emocionales? México: Editorial Hermes, 1995.

Instituto Nacional de Estadísticas y Censos. IX Censo Nacional de Población: características sociales y demográficas. San José, Costa Rica: Instituto Nacional de Estadísticas y Censos, 2002.

Kaliyaperumal, K. "Guideline for conducting a knowledge, attitude and practice (KAP) Study". AECS Illumination IV (1). 2004.

Kaufert, Patricia. "Myth and the menopause". Sociology of Health and Illness 4 (2). England and Wales: Blackwell Publishing Ltd Company, 1982. 
Kerlinger, Fred y Howard, Lee. Investigación del comportamiento. México: MacGrawHill, 2002.

Laurence, Leslie y Weinhouse, Beth. Outrageous practices. The alarming truth about medicine mistreats women. New York: Fawcett Columbine, 1994.

Lock, Margaret. Encounters with aging: mythologies of menopause in Japan and North America. California, United States of America: University of California Press, 1995.

López, Nancy. "La familia, el trabajo y el propio cuerpo en la 'edad crítica”. Mujer y sociedad en América Latina. Feijoo, María del Carmen (comp.). Buenos Aires: Consejo Latinoamericano de Ciencias Sociales (CLACSO), 1991.

López, Zeneida y Méndez, Ana Lorena. "Programa educativo sobre climaterio y menopausia, área de salud Montes de Oro, Miramar, Puntarenas". [Práctica dirigida de Licenciatura en Enfermería]. Universidad de Costa Rica, 2005.

Losoviz, Alicia. Menopausia ¿Qué me está pasando? Mitos y realidades del climaterio. Buenos Aires, Argentina: Catálogos, 2000.

Madden, Rose Mary y Hidalgo, Ana Lorena. "Menopausia: una nueva forma de neocolonialismo ideológico y económico". Revista Medicina Legal de Costa Rica 21 (1). Heredia, Costa Rica: Asociación Costarricense de Medicina Forense, 2004: 1-7.

Mitchinson, Wendy. "No longer the same woman: medical perceptions of menopause, 1900-1950". Canadian Bulletin of Medical History 23. 2006.

Moncarz, Esther. “¿Una extraña entre nosotras? Mujeres maduras, cuerpo y subjetividad". La revolución de las canas. Reflexiones $y$ experiencias sobre el envejecer de las mujeres. Gómez, Adriana (ed.). Santiago, Chile: Red de Salud de las Mujeres Latinoamericanas y del Caribe, 1999.

Páramo, Pablo y Otálvaro, Gabriel. "Investigación Alternativa: por una distinción entre posturas epistemológicas y no entre métodos". Cinta de Moebio 25. Santiago, Chile: Universidad de Chile, 2006.

Plaza, Marta. "Sobre el concepto de 'violencia de género'. Violencia simbólica, lenguaje, representación". Extravío. Revista electrónica de literatura comparada 2. España: Universidad de Valencia, 2007: 132-145.

Pozo, Juan Ignacio. Adquisición de conocimiento. Madrid, España: Ediciones Morata, 2003.

Quintana, José. Psicología de la conducta. Análisis histórico. Madrid, España: Editorial Alhabama Mexicana, 1985.

Reis, Harry y Judd, Charles. Handbook of research methods in social and personality psychology. Cambridge: Cambridge University Press, 2000.

Rodríguez, Rosa María. Foucault y la genealogía de los sexos. México: Editorial Anthropos, 1999.

Rojas, Marielos; Balmaceda, Gretel y Rojas, Ana. Análisis Basado en género: una herramienta metodológica para la planificación en salud. San José, Costa Rica: Imprenta Nacional, 2007.

Uberoi, Patricia y Badahur, Tarin. The woman's body in midlife: sociocultural and medical perspectives from South Asia. En: http://www.igs.ocha.ac.jp/ igs2/igs/IGS_publication/journal/ 4/ journal04013.pdf.2001 [Consultado el 8 de Julio de 2009].

Uncu, Y; Alper, Z; Ozdemir, H; Bilgel, N y Uncu, G. "The perception of menopause and hormone therapy among women in Turkey". Climacteric 10. International Menopause Society, 2007: 63-71.

Villarreal, Cecilia. "La menopausia: un proceso de crecimiento". [Tesis de Maestría en Estudios de la Mujer]. Universidad de Costa Rica/Universidad Nacional, 1996.

Vladislavovna, Svetlana. "Autopercepción del estado de salud en climatéricas derechohabientes del Instituto Mexicano del Seguro Social”. Salud pública de México 50 (5). 2008: 390-396. 
World Health Organization. Advocacy, communication and social movilization for TB control: a guide to developing knowledge, attitude and practice surveys. Geneva, Switzerland: WHO Press, 2008.

Zúñiga, Xinia. "Análisis de sesgos de género en las estadísticas de la población estudiantil que ingresó por primera vez a la UNED, en el año 2002". [Tesis de Maestría en estudio de la violencia social y familiar]. Universidad Estatal a Distancia, 2004.

Fecha de ingreso: 10/04/2012 Fecha de aprobación: 1/06/2012 